\title{
Effects of temperature at constant air dew point on leaf carboxylation efficiency and $\mathrm{CO}_{2}$ compensation point of different leaf types
}

\author{
J.A. Weber ${ }^{1 *}$, J.D. Tenhunen ${ }^{2}$ and O.L. Lange ${ }^{3}$ \\ ${ }^{1}$ Biological Station, University of Michigan, Ann Arbor, Michigan 48109-1048, USA, \\ ${ }^{2}$ Systems Ecology Research Group, San Diego State University, San Diego, California 92182, USA, and \\ ${ }^{3}$ Lehrstuhl für Botanik II der Universität Würzburg, Mittlerer Dallenbergweg 64, D-8700 Würzburg, Federal Republic of Germany
}

\begin{abstract}
The effect of temperature on photosynthesis at constant water-vapor pressure in the air was investigated using two sclerophyll species, $A r-$ butus unedo and Quercus suber, and one mesophytic species, Spinacia oleracea. Photosynthesis and transpiration were measured over a range of temperatures, $20-39^{\circ} \mathrm{C}$. The external concentration of $\mathrm{CO}_{2}$ was varied from $340 \mu$ bar to near $\mathrm{CO}_{2}$ compensation. The initial slope (carboxylation efficiency, $\mathrm{CE}$ ) of the photosynthetic response to intercellular $\mathrm{CO}_{2}$ concentration, the $\mathrm{CO}_{2}$ compensation point $(\Gamma)$, and the extrapolated rate of $\mathrm{CO}_{2}$ released into $\mathrm{CO}_{2}$-free air $\left(R_{i}\right)$ were calculated. At an external $\mathrm{CO}_{2}$ concentration of $320-340 \mu \mathrm{bar}$ $\mathrm{CO}_{2}$, photosynthesis decreased with temperature in all species. The effect of temperature on $\Gamma$ was similar in all species. While CE in $S$. oleracea changed little with temperature, CE decreased by $50 \%$ in $Q$. suber as temperature increased from 25 to $34^{\circ} \mathrm{C}$. Arbutus unedo also exhibited a decrease in $\mathrm{CE}$ at higher temperatures but not as marked as $Q$. suber. The absolute value of $R_{l}$ increased with temperature in $S$. oleracea, while changing little or decreasing in the sclerophylls. Variations in $\Gamma$ and $R_{l}$ of the sclerophyll species are not consistent with greater increase of respiration with temperature in the light in these species compared with $S$. oleracea.
\end{abstract}

Key words: Carboxylation efficiency - Compensation point $\left(\mathrm{CO}_{2}\right)$ - Photosynthesis (temperature, humidity) - Sclerophyll - Transpiration.

\footnotetext{
* To whom correspondence should be addressed

Abbreviations and symbols: $A=$ net photosynthetic rate; $C_{a}$ and $C_{i}=\mathrm{CO}_{2}$ concentration in the air and in the intercellular airspace of the leaf, respectively; $\mathrm{CE}=$ carboxylation efficiency; $E=$ transpiration rate; $R_{l}=\mathrm{CO}_{2}$ release into $\mathrm{CO}_{2}$-free air estimated from extrapolation to $0 \mu$ bar $\mathrm{CO}_{2} ; T_{l}=$ leaf temperature; $\mathrm{VPD}=$ difference in water-vapor pressure between mesophyll and air; $\Gamma=\mathrm{CO}_{2}$ compensation point
}

\section{Introduction}

Midday stomatal closure is characteristic of many species growing in arid and semi-arid environments (Schulze et al. 1974, $1975 \mathrm{a}$, b; Lange and Meyer 1979; Tenhunen et al. 1984). Decreased stomatal conductance during midday, which is often dependent on the humidity of the air (Lange et al. 1971; Lösch and Tenhunen 1981), can result in reduced transpirational water loss. Simultaneously, $\mathrm{CO}_{2}$ uptake through photosynthesis also decreases. However, Schulze et al. (1975a) found that the internal $\mathrm{CO}_{2}$ concentration $\left(C_{i}\right)$ in leaves of Prunus armeniaca growing in the Negev Desert did not decrease during midday stomatal closure. More recently, Tenhunen et al. (1984) found that leaves of Quercus suber exhibited a strong midday depression of photosynthesis and transpiration rates during the summer dry season in the evergreen scrub near Lisbon, Portugal. Even though leaf conductance decreased by a factor of four, $C_{i}$ of the leaves remained essentially constant throughout the day. Diurnal variation of the initial slope of photosynthetic response to $\mathrm{CO}_{2}\left(A: C_{i}\right.$ response) was determined by exposing leaves to different $\mathrm{CO}_{2}$ concentrations over a series of days which had similar variation in light, temperature, and humidity. This slope, or carboxylation efficiency (CE; Forrester et al. 1966), declined strongly with increasing leaf temperatures above $30^{\circ} \mathrm{C}$, accompanied by increasing vapor-pressure difference between leaf and air (VPD). Similar behaviour was found with Arbutus unedo (see Beyschlag 1984).

The present research had three goals: i) to determine whether the variation in CE measured in the field could be reproduced under similar conditions in the laboratory by exposing the leaves to stepwise changes in $\mathrm{CO}_{2}$ concentration, ii) to see if other species behaved in a similar manner, and 
iii) to examine more closely the relationship between photosynthesis and transpiration as CE varies. Arbutus unedo and Quercus suber, sclerophyllous trees found in the evergreen scrub of Portugal (Tenhunen et al. 1981), were chosen because they exhibit strong midday stomatal closure. These species are distributed along the coast of the Iberian Peninsula and along the northern shore of the Mediterranean Sea in more maritime areas (Walter and Straka 1970, p. 309). As with many evergreen sclerophylls, these species are apparently well adapted to survive the prolonged summer drought that is typical of their normal habitat. As a comparison, Spinacia oleracea (spinach) was chosen because it has a mesophytic leaf type and is commonly studied in the laboratory. Although there are no previous data describing the effect of leaf temperature on CE in $S$. oleracea, we might expect that it should behave in a manner similar to other mesophytic species, such as Triticum aestivum (Jolliffe and Tregunna 1968; Ku and Edwards 1977).

\section{Materials and methods}

The plants of $A$. unedo were collected at the Research Station Quinta São Pedro, Sobreda, Portugal near Lisbon. Plants of Q. suber were obtained from the Department of Forestry, Technical University of Lisbon. During the autumn and winter the potted plants were kept in a greenhouse of the Botanical Garden in Würzburg, FRG; during spring and summer they were placed outside. The plants of S. oleracea (cv. Yates) were grown from seed in greenhouses at Würzburg. In one experiment, a plant of $S$. oleracea was not watered for $3 \mathrm{~d}$ before measurements were made. Pre-dawn water potential, measured with a Scholander pressure chamber, was -14 bar for desiccated plants compared with -5 bar for well-watered plants.

The measurement apparatus was a portable mini-cuvette system (Lange et al. 1984) built by Heinz Walz Mess- und Regeltechnik, Effeltrich, FRG. Absolute $\mathrm{CO}_{2}$ concentration was measured with an infrared gas analyzer (Binos 1; Leybold-Heraeus, Hanau, FRG). Relative humidity in the leaf chamber was measured with a capacitance-type sensor (Coreci, Lyon, France). Differential $\mathrm{CO}_{2}$ and water-vapor concentrations across the mini-cuvette were measured with a dual-channel gas analyzer (Binos 1). For a more complete description of the mini-cuvette, control and analyzing systems see Lange and Tenhunen (1984). Photosynthetic photon flux density was $1190 \mu \mathrm{mol} \mathrm{m} \mathrm{m}^{-2} \mathrm{~s}^{-1}$ which was saturating for all species at the $\mathrm{CO}_{2}$ concentrations used. Various $\mathrm{CO}_{2}$ concentrations were produced by mixing $\mathrm{CO}_{2}$-free air with pure $\mathrm{CO}_{2}$ using massflow controllers (Walz, Effeltrich, FRG). Three to four external $\mathrm{CO}_{2}$ concentrations between 75 and $340 \mu$ bar were used to determine the initial slope of the $A: C_{i}$ response curve. Vapor pressure of gas entering the leaf chamber was set by first saturating the gas with water vapor in a sparging bottle then passing the water-saturated gas through a cold trap at the desired dewpoint temperature. In order to simulate the natural variation in relative humidity with temperature, the absolute humidity entering the chamber was held constant, producing an increase in the vapor-pressure difference between leaf mesophyll and air (VPD) with increasing temperature (Table 1).

Leaf temperature $\left(t_{l}\right)$ was changed in $3-5^{\circ} \mathrm{C}$ steps starting at $20-25^{\circ} \mathrm{C}$ depending on the species. At least once with each species, $T_{t}$ was adjusted to the starting temperature at the end of the experiment. The data for each replicate were taken from a single leaf within a few hours. Calculation of slopes (carboxylation efficiency, $\mathrm{CE})$, x-intercepts $\left(\mathrm{CO}_{2}\right.$ compensation points, $\Gamma$ ), and y-intercepts (an estimate of $\mathrm{CO}_{2}$ release into $\mathrm{CO}_{2}$-free air, $R_{l}$, Ludlow and Jarvis, 1971) were made using lest-squares linear regression of all the points shown in Fig. 1. Each experiment was replicated. Calculation of the intercellular $\mathrm{CO}_{2}$ concentration $\left(C_{i}\right)$ was according to the equations of Leuning (1983). Boundary-layer conductance in the cuvette was assumed to be $0.05 \mathrm{~m} \mathrm{~s}^{-1}$ (Lange and Tenhunen 1984).

\section{Results}

Responses of net photosynthetic rate $(A)$ to intercellular $\mathrm{CO}_{2}$ concentration $\left(C_{i}\right)$ at constant irradiance and different combinations of leaf temperature $\left(T_{l}\right)$ and air-to-leaf vapor-pressure difference (VPD) are shown for all three species in Fig. 1. Note that the scale of the ordinant axes is different for each of the three species. Variation of VPD with leaf temperature is shown in Table 1. We will use the designation $T_{l}$ :VPD to indicate that both factors changed in parallel when temperature was changed. The lesser increase in VPD with $T_{l}$ for well-watered $S$. oleracea resulted primarily from a much higher transpiration rate than the other species (Fig. 3A). Net photosynthetic rate measured at $320-340 \mu$ bar external $\mathrm{CO}_{2}$ concentration $\left(C_{a}\right)$ and $21 \% \mathrm{O}_{2}$ declined with increasing $T_{l}$ :VPD in all three species (Fig. 2A). The rate of decline in $A$ with $T_{l}$ above $30^{\circ} \mathrm{C}$ was quite similar for well-watered $S$. oleracea and $A$. unedo, and for water-stressed $S$. oleracea and $Q$. suber. The percent reduction was greater in $Q$. suber and waterstressed $S$. oleracea than in $A$. unedo and wellwatered S. oleracea. Returning the temperature to $25^{\circ} \mathrm{C}$ caused the photosynthetic rate to increase to somewhat less than the original values. In both $S$. oleracea and $A$. unedo, A was not strongly affected by $T_{l}$ :VPD at lower temperatures, $20-25^{\circ} \mathrm{C}$ and $25-30^{\circ} \mathrm{C}$, respectively, whereas at higher $T_{l}$ :VPD, A declined more rapidly. Above $25^{\circ} \mathrm{C}$, $Q$. suber exhibited a strong and continual decrease in A with increasing $T_{l}$ :VPD.

The results of the regression analysis of the data in Fig. 1 are plotted as functions of $T_{l}$ and VPD in Fig. $2 \mathrm{C}-\mathrm{H}$. While the evergreen species had generally higher values of $\Gamma$ than spinach (Fig. 2C) at a given $T_{l}$, there was essentially no difference when $\Gamma$ was plotted as a function of VPD (Fig. 2D). The variation of CE with $T_{l}$ :VPD was quite different among the species (Fig. 2E-F). In $S$. oleracea there was a small increase in $\mathrm{CE}$ to $33^{\circ} \mathrm{C}$, followed by a decline. For $Q$. suber there was a decline in $\mathrm{CE}$ with increasing temperature. 


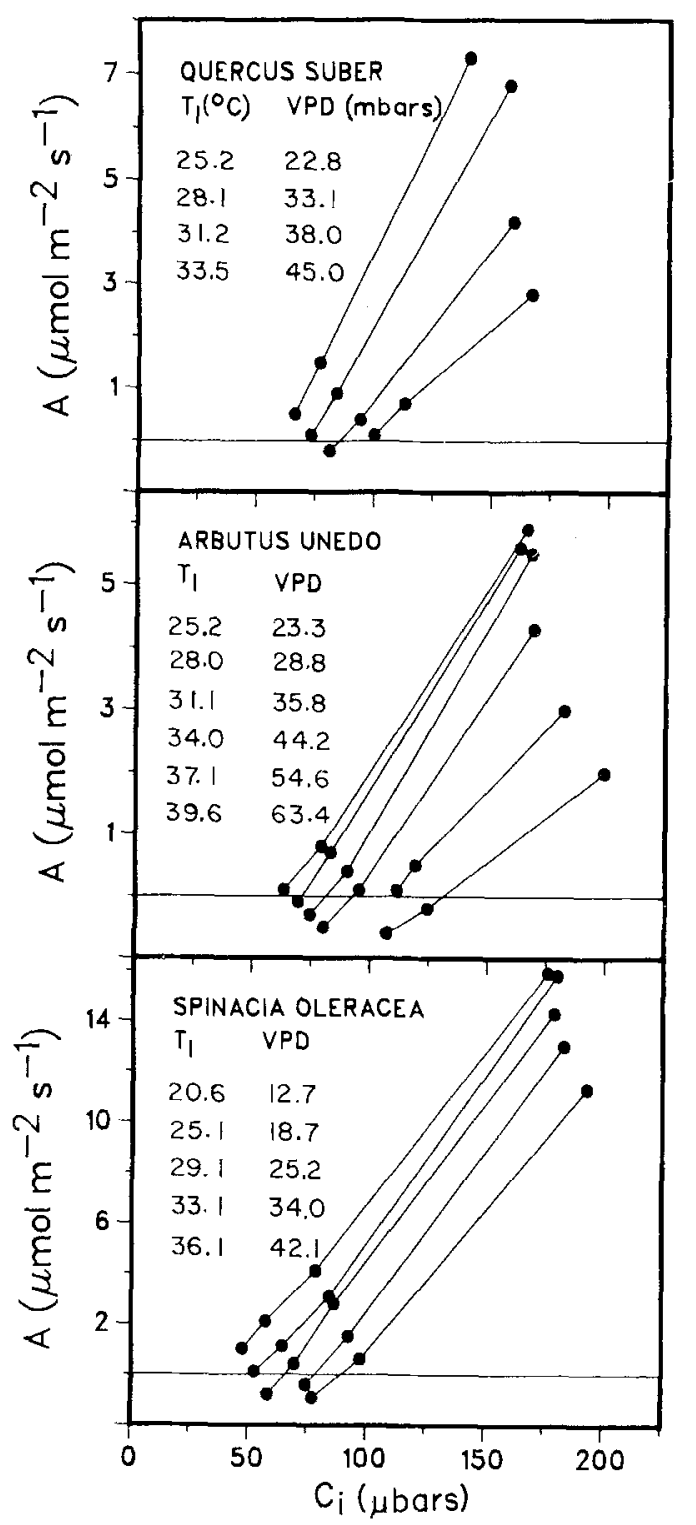

Fig. 1. Photosynthetic rates (A) of Quercus suber, Arbutus unedo, and Spinacia oleracea as functions of calculated internal $\mathrm{CO}_{2}$ concentration and leaf temperature $\left(T_{i}\right) \cdot T_{i}\left({ }^{\circ} \mathrm{C}\right)$ and VPD (mbar) are indicated next to each of the curves

Over the same temperature range $\left(25-34^{\circ} \mathrm{C}\right) \mathrm{CE}$ declined by about $50 \%$ in $Q$. suber compared with no change in $S$. oleracea. In $A$. unedo, CE increased with $T_{l}$ up to about $32^{\circ} \mathrm{C}$; above this temperature $\mathrm{CE}$ declined, reaching $50 \%$ of the maximum at $39^{\circ} \mathrm{C}$. The values for CE were greater in $S$. oleracea than in the two evergreens, reflecting the higher photosynthetic capacity in $S$. oleracea. The extrapolated $\mathrm{CO}_{2}$ release into $\mathrm{CO}_{2}$-free air, $R_{l}$, varied differently with $T_{l}$ :VPD among the three species (Fig. 2G-H). Spinacia oleracea had the lowest $R_{i}$ at any given temperature. In $S$. oleracea, the overall trend is a decrease in $R_{i}$; in $Q$. suber, an in-
Table 1. Variation of leaf temperature $\left(T_{l}\right)$, air-to-leaf vaporpressure difference (VPD), vapor pressure in the air surrounding the leaf (VPA), and vapor pressure of the gas entering the leaf chamber (VPin). Mean and SD for $T_{l}, V P A$, and VPD

\begin{tabular}{|c|c|c|c|c|}
\hline Species & $\begin{array}{l}T_{i} \\
\left({ }^{\circ} \mathrm{C}\right)\end{array}$ & $\begin{array}{l}\text { VPA } \\
\text { (mbar) }\end{array}$ & $\begin{array}{l}\text { VPD } \\
\text { (mbar) }\end{array}$ & $\begin{array}{l}\text { VPin } \\
\text { (mbar) }\end{array}$ \\
\hline $\begin{array}{c}\text { Quercus } \\
\text { suber }\end{array}$ & $\begin{array}{l}25.2 \pm 0.1 \\
28.1 \pm 0.1 \\
31.2 \pm 0.1 \\
33.5 \pm 0.1\end{array}$ & $\begin{array}{r}10.2 \pm 0.3 \\
9.2 \pm 0.1 \\
8.8 \pm 0.4 \\
8.4 \pm 0.2\end{array}$ & $\begin{array}{l}22.8 \pm 0.4 \\
30.1 \pm 0.2 \\
38.0 \pm 0.5 \\
45.0 \pm 0.3\end{array}$ & 7.0 \\
\hline $\begin{array}{r}\text { Arbutus } \\
\text { unedo }\end{array}$ & $\begin{array}{l}25.2 \pm 0.1 \\
28.0 \pm 0.1 \\
31.1 \pm 0.1 \\
34.0 \pm 0.1 \\
37.1 \pm 0.1 \\
39.6 \pm 0.1\end{array}$ & $\begin{array}{r}9.4 \pm 0.1 \\
9.8 \pm 0.2 \\
10.4 \pm 0.2 \\
10.3 \pm 0.2 \\
10.2 \pm 0.2 \\
10.6 \pm 0.3\end{array}$ & $\begin{array}{l}23.3 \pm 0.1 \\
28.8 \pm 0.2 \\
35.8 \pm 0.2 \\
44.2 \pm 0.2 \\
54.6 \pm 0.2 \\
63.4 \pm 0.3\end{array}$ & 7.1 \\
\hline $\begin{array}{l}\text { Spinacia } \\
\quad \text { oleracea }\end{array}$ & $\begin{array}{l}20.6 \pm 0.1 \\
25.1 \pm 0.1 \\
29.1 \pm 0.2 \\
33.1 \pm 0.1 \\
36.1 \pm 0.1\end{array}$ & $\begin{array}{l}11.8 \pm 0.4 \\
14.0 \pm 0.2 \\
15.5 \pm 0.7 \\
17.1 \pm 1.0 \\
18.5 \pm 0.8\end{array}$ & $\begin{array}{l}12.7 \pm 0.5 \\
18.7 \pm 1.0 \\
25.2 \pm 1.0 \\
34.0 \pm 1.1 \\
42.1 \pm 1.0\end{array}$ & 9.9 \\
\hline $\begin{array}{c}\text { Spinacia } \\
\text { oleracea } \\
\text { (water- } \\
\text { stressed) }\end{array}$ & $\begin{array}{l}25.7 \pm 0.1 \\
28.1 \pm 0.1 \\
30.6 \pm 0.5 \\
33.0 \pm 0.1\end{array}$ & $\begin{array}{l}9.0 \pm 0.4 \\
8.3 \pm 0.7 \\
7.9 \pm 0.4 \\
7.0 \pm 0.4\end{array}$ & $\begin{array}{l}24.4 \pm 0.1 \\
30.4 \pm 0.9 \\
37.0 \pm 1.6 \\
43.7 \pm 0.4\end{array}$ & 6.2 \\
\hline
\end{tabular}

crease; and in $A$. unedo, a decrease followed by an increase.

Spinacia oleracea which had not been water stressed had a much higher stomatal conductance to water vapor $(\mathrm{G})$ than the other species (Fig. 3C$D)$; however, after water stress $\mathrm{G}$ was reduced and more sensitive to changes in $T_{i}:$ VPD. The stomatal response of the evergreen species to increasing $T_{l}:$ VPD was greater than that of the unstressed $S$. oleracea, but similar to the stressed $S$. oleracea. Changes in $G$ could also affect photosynthetic rate through changes in $C_{i}$. For our studies, $C_{i}$ (Fig. 3E-F) changed little (S. oleracea and A. un$e d o$ ) or varied in a manner inconsistent with limitation by $\mathrm{G}$ (i.e., $C_{i}$ increased with decreasing $\mathrm{G}$ in $Q$. suber and water-stressed $S$. oleracea at $T_{l}$ above $29^{\circ} \mathrm{C}$ ). Only with the increase in temperature from $26^{\circ}$ to $29^{\circ} \mathrm{C}$ in the water-stressed $S$. oleracea did $C_{i}$ decline. Lower $C_{i}$ in water-stressed compared with non-water-stressed $S$. oleracea may indicate a greater limitation by $G$, although water stress has been shown to reduce photosynthetic capacity as well as leaf conductance (Bunce 1977; Collatz et al. 1976; Collatz 1977; Kaiser 1984; Matthews and Boyer 1984).

The fact that $G$ had different sensitivities to increasing $T_{l}$ :VPD in the different species could reflect a difference in the relationship of photosyn- 

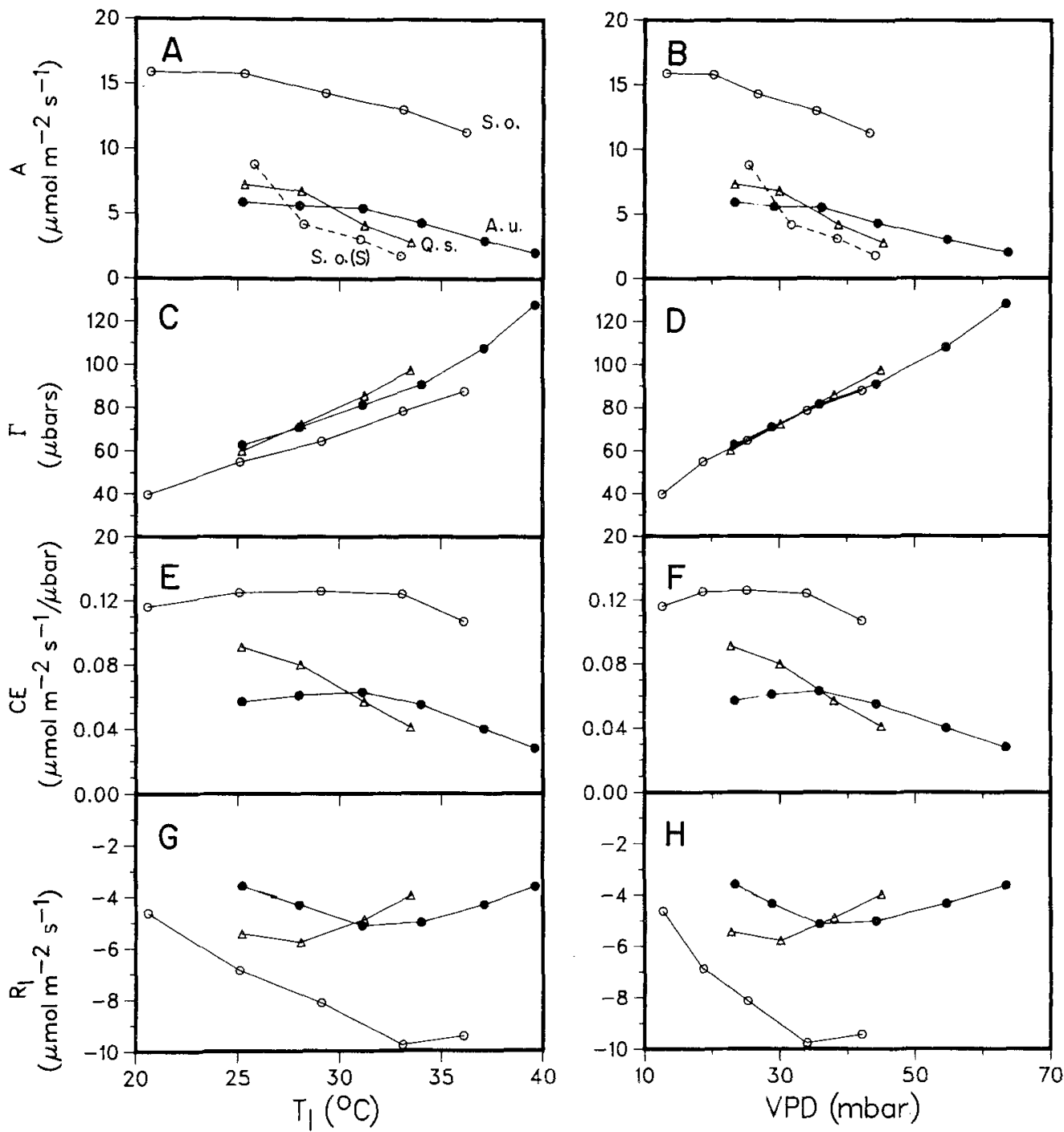

Fig. 2 A-H. Variation with leaf temperature $\left(T_{l}\right)$ and air-to-leaf vapor-pressure difference (VPD) of: photosynthesis (A) at $320-340 \mu$ bar $\mathrm{CO}_{2}$ external to the leaves, $\mathrm{CO}_{2}$ compensation point $(\Gamma)$, initial slope of the $A: C_{i}$ response $(C E)$, and the extrapolated release of $\mathrm{CO}_{2}$ into $\mathrm{CO}_{2}$ free air $\left(R_{l}\right)$. The values of $\mathrm{CE}, \Gamma$, and $R_{l}$ were derived from linear regressions on the data in Fig. 1 . (A) Quercus suber, Q.s., (•) Arbutus unedo, A.u., (o) Spinacia oleracea, S.o.; dashed line refers to data from water-stressed plant (S)

thesis $(A)$ to transpiration $(E)$. In well-watered $S$. oleracea, $E$ increased by more than three fold over the temperature range (Fig. $3 \mathrm{~A}$ ); however, in water-stressed $S$. oleracea, E declined with increasing $T_{l}$ :VPD. For both $Q$. suber and $A$. unedo, $\mathrm{E}$ initially increased then decreased with increasing $T_{l}$. In Fig. 4, $A$ measured at $C_{a}$ of $320-340 \mu$ bar $\mathrm{CO}_{2}$ but different $T_{l}: \mathrm{VPD}$ is plotted as a function of $\mathrm{E}$. The arrows indicate increasing $T_{l}: \mathrm{VPD}$. Also shown in Fig. 4 are lines representing a constant $A: E$ ratio. For $S$. oleracea, increasing $E$ was correlated with a decrease in $A$; however, when the plant was water-stressed the response was reversed so that $E$ and $A$ declined together with increasing $T_{l}$ :VPD. In $A$. unedo and $Q$. suber, $E$ and $A$ were initially inversely related, but became almost directly proportional at higher $T_{l}$. One result of the responses of $E$ and $A$ to $T_{1}$ was that the A:E ratio for the sclerophylls and for water-stressed $S$. oleracea decreased less with increasing $T_{l}$ :VPD than for the unstressed S. oleracea.

\section{Discussion}

Recent data on Quercus suber (Tenhunen et al. 1984) and Arbutus unedo (Beyschlag 1984) show that midday depression in photosynthesis under natural conditions is not necessarily linked through reduction in $C_{i}$ caused by stomatal closure. In these species, and others (Schulze et al. 1975a), $C_{i}$ re- 

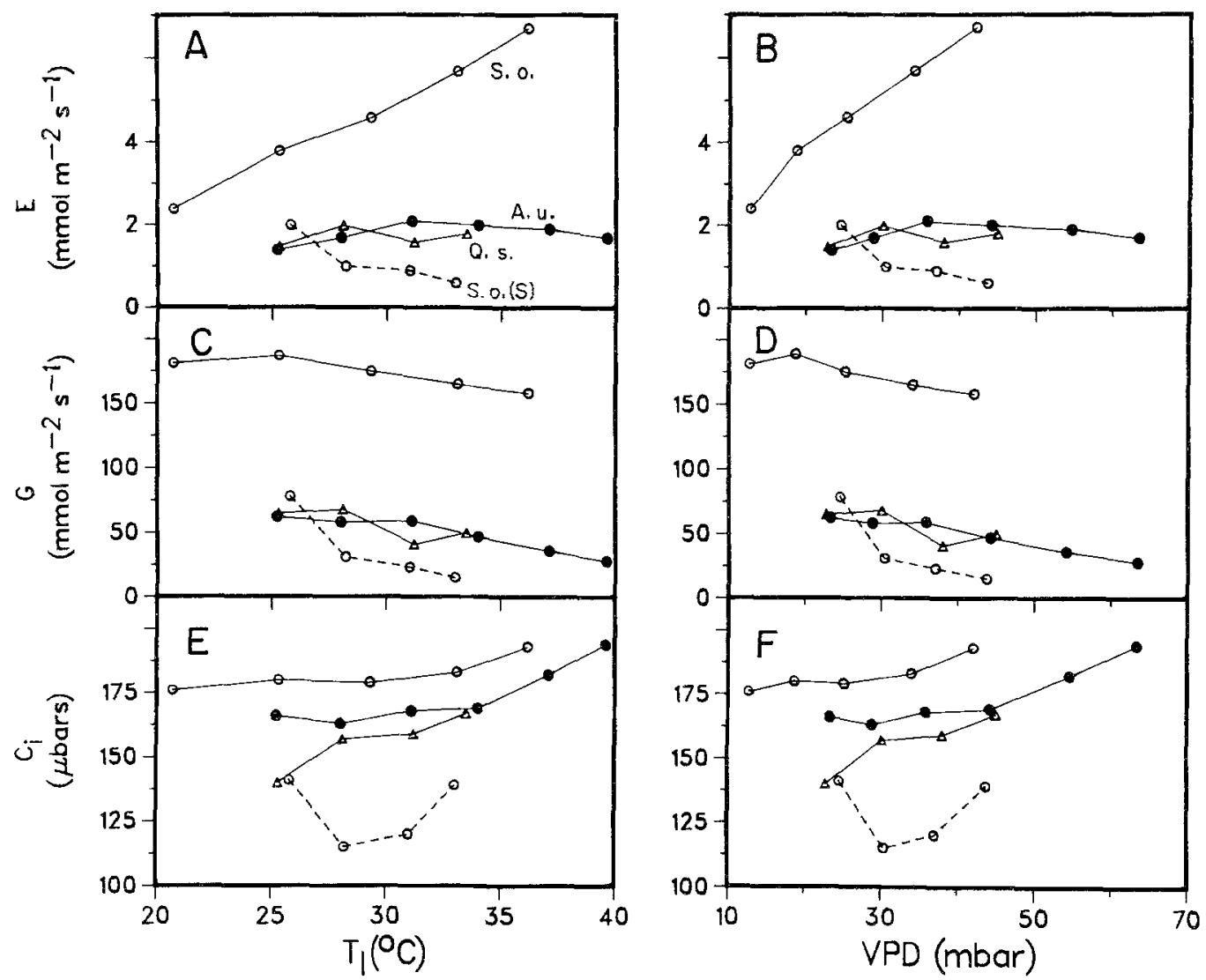

Fig. 3A-F. Variation of transpiration rate $(E)$, leaf conductance $(G)$, and intercellular $\mathrm{CO}_{2}$ concentration $\left(C_{i}\right)$ with leaf temperature $\left(T_{l}\right)$ and air-to-leaf vapor-pressure difference $(V P D)$ at external $\mathrm{CO}_{2}$ concentration of $320-340 \mu$ bar and saturating photosynthetic

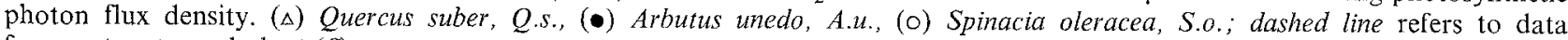
from water-stressed plant $(S)$

mained remarkably constant throughout the period of depressed gas exchange during the hottest and driest part of the day. More detailed examination of the data of Tenhunen et al. (1984) and Beyschlag (1984) showed that photosynthetic characteristics change with temperature at constant external water vapor pressure, in particular the initial slope of the $A: C_{i}$ response (CE) declines with increasing $T_{l}$ :VPD. While $T_{l}$ is an obvious factor that can affect photosynthetic response, there are reports that VPD either through transpiration rate (e.g., Sharkey 1984) or directly (Reseman and Raschke 1984) can affect photosynthetic response. Under natural conditions, $T_{l}$ and VPD change in parallel (e.g. Schulze et al. 1974; Tenhunen et al. 1984), so that separating effects of these two factors using data from the field is difficult. Since we simulated the temperature and humidity conditions in the field, our data do not allow for unequivocal separation of these two factors.

Most published reports indicate little effect of $T_{l}$ on CE over a broad range of $T_{l}$, for instance, in Tritium aestivum (Jolliffe and Tregunna 1968;
$\mathrm{Ku}$ and Edwards 1977), Phaseolus vulgaris (Peisker et al. 1979), Gossypium hirsutum (Troughton and Slatyer 1969), and Eucalyptus pauciflora (Kirschbaum and Farquhar 1984). However, Doley and Yates (1976) found a large effect of temperature on mesophyll resistance (calculated according to Ludlow and Jarvis (1971) assuming $\Gamma=0$ ) in the $C_{4}$ grass, Astrebla lappacea. If $\mathrm{CE}$ in $C_{3}$ plants is controlled by the characteristics of ribulose-1,5bisphosphate carboxylase/oxygenase as proposed by Farquhar et al. (1980) and von Caemmerer and Farquhar (1981), interpretation of our data as a temperature effect would require a temperature effect on the enzyme such that its activity would decline with increasing $T_{l}$ within the temperature range studied.

As noted above, other possibile explainations of the variation we found are direct effects of transpiration rate or VPD on photosynthetic metabolism. Thompson et al. (1965), who investigated the effect of humidity on the photosynthetic response to temperature in Citrus jambhiri, found a definite depression in photosynthesis at high temperature 


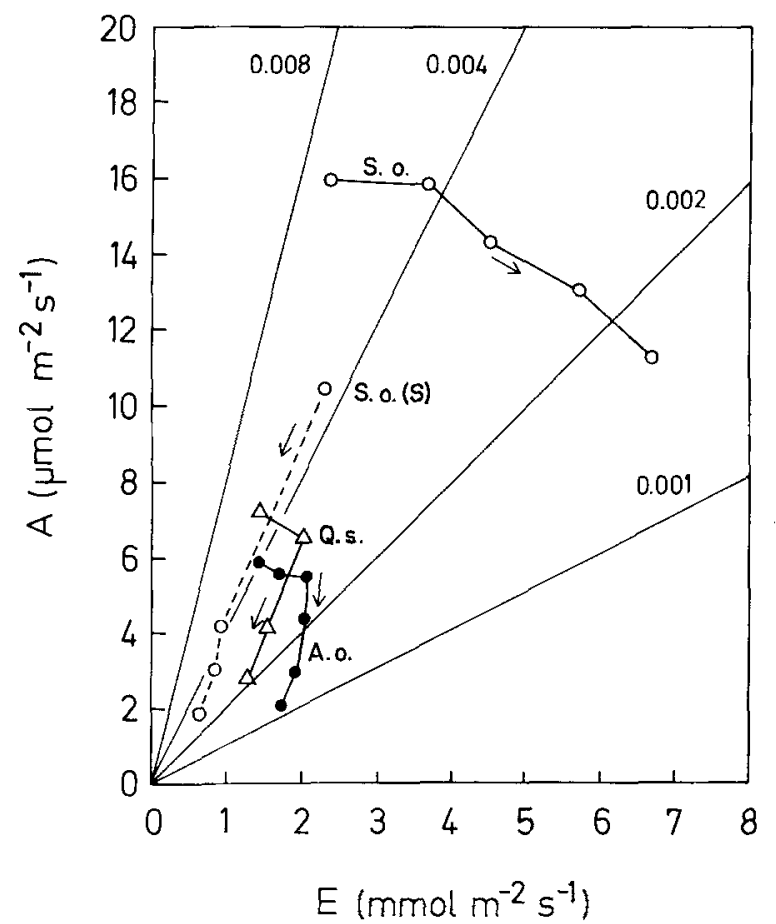

Fig. 4. Relationship between transpiration $(E)$ and photosynthesis $(A)$ at $320-340 \mu$ bar $\mathrm{CO}_{2}$ external. Lines marked 0.001 to 0.008 indicate constant $A / E$ in mol $\mathrm{CO}_{2} / \mathrm{mol} \mathrm{H}_{2} \mathrm{O}$. Increasing leaf temperature and VPD is indicated by arrows next to each curve. $(\Delta)$ Quercus suber, Q.s., (•) Arbutus unedo, A.u., (o) Spinacia oleracea, S.o., dashed line refers to data from water-stressed plant $(S)$

when vapor pressure in the air surrounding the leaf (VPA) was low, but not when VPA was high. However, they did not present data on $C_{i}$ for their experiments. Jenson (1975) in salt-stressed Phaseolus vulgaris and Leach (1979) in Triticum aestivum found a decrease in CE with increasing VPD. Neither Jolliffe and Tregunna (1968), who maintained a constant water-vapor pressure entering the leaf chamber, nor Ku and Edwards (1977), who maintained a constant VPD of 11-15 mbar, found a major change in CE with $T_{l}$ in Triticum aestivum. More recently, Forseth and Ehleringer (1983), Ball and Farquhar (1984), and Sharkey (1984) found that increasing VPD caused a decline in the $\mathrm{CO}_{2}^{-}$ saturated rate of photosynthesis, but no change in CE. Preliminary data on $Q$. suber indicated that increasing VPD at constant $T_{l}$ caused a reduction in $\mathrm{A}$ at $340 \mu$ bar $\mathrm{CO}_{2}$. Sharkey (1984) proposed that localized water stress produced by increased transpiration leads to reduced photosynthetic capacity. However, Bunce (1984) presented data on Chenopodium album and Helianthus annuus in which A declined with increasing VPD (19-30 mbar) but was not always related to increased E. Reseman and Raschke (1984) showed that above 30 mbar VPD, CE declined in Arbutus unedo. Raschke (1982) has reported that application of abscisic acid to leaves can reduce $\mathrm{CE}$ and the $\mathrm{CO}_{2}$-saturated rate of photosynthesis. He has proposed that increased VPD may in some way induce the production and-or redistribution of abscisic acid inside the mesophyll cells.

Considering the data in Fig. 4, a simple increase in E cannot explain the change in A observed. Only in $A$. unedo and $Q$. suber at low $T_{I}$ and VPD, and in unstressed Spinacia oleracea was decreased $A$ associated with increased $E$. In all other cases $\mathrm{E}$ and $\mathrm{A}$ changed almost proportionally. A change in the proportion between photosynthetic and respiratory activity could produce a change in the shape of the $A: \mathrm{C}_{i}$ response. However, if respiratory rate increased more rapidly with $T_{l}$ and-or VPD in $A$. unedo and $Q$. suber compared with $S$. oleracea, then a relatively greater increase in $\Gamma$ should be expected. Our data do not support this possibility, since the variation in $\Gamma$ with $T_{l}$ :VPD was not appreciably different among the three species (Fig. 2). Bauer and Martha (1981) and Bauer et al. (1983) have shown that for a wide range of species, $\Gamma$ is essentially the same at a given $T_{l}$ and varies similarly with $T_{l}$. The generally higher $\Gamma$ at a given $T_{l}$ for the evergreen species could be the result of a relatively higher mitochondrial respiratory rate in the light. A more direct means of estimating respiratory activity in the light is determining the y-intercept of the $A: C_{i}$ response (Ludlow and Jarvis 1971). The fact that the y-intercept, an estimate of $\mathrm{CO}_{2}$ released into $\mathrm{CO}_{2}$-free air $\left(R_{i}\right)$, increased or changed little with $T_{i}$ and-or VPD in $Q$. suber and $A$. unedo leads to the conclusion that respiratory rate did not increase markedly, and may have even declined. On the other hand, $R_{l}$ declined in $S$. oleraceae with increasing $T_{l}$ :VPD up to $33^{\circ} \mathrm{C}$. Thus, we can conclude that for $Q$. suber and $A$. unedo the variation in $R_{l}$ and $\Gamma$ with increasing temperature is not consistent with an increase in respiratory activity.

Whatever the mechanism, change in $T_{l}$ :VPD from 25 to $35^{\circ} \mathrm{C}$ can have a major effect on the initial slope of the $A: C_{i}$ response of some species. This response is especially evident in Quercus suber and confirms the response measured in the field (Tenhunen et al. 1984). The combined responses of $\Gamma$ and $R_{l}$ in the sclerophylls strongly indicates that there is a reversible inactivation of the photosynthetic system by increasing $T_{l}: \mathrm{VPD}$, resulting in a reduction of $\mathrm{CE}$. The combined effect of decreasing $\mathrm{CE}$ and increasing $\Gamma$ in the sclerophylls is a larger reduction in A with increasing $T_{l}: \mathrm{VPD}$ and maintenance of a greater $C_{i}$ at a given stomatal 
conductance to water vapor than if only $\Gamma$ increased, as in $S$. oleracea. The relevance of this response may be in the avoidance of low $C_{i}$ values which at high irradiance, VPD, and $T_{l}$ might lead to photoinhibition (Powles and Critchley 1980) when stomates close during the midday depression. Further studies are needed to separate clearly the effects of temperature from those of VPD on photosynthetic response.

We would like to thank Dr. Werner Kaiser for providing the plants of Spinacia oleracea and Dr. Klaus Winter for comments on the manuscript. This work was supported by the Deutsche Forschungsgemeinschaft. Additional support for J.A.W. was provided by a contract (DE-AC02-76EY02164) from the U.S. Department of Energy to David M. Gates.

\section{References}

Ball, M.C., Farquhar, G.D. (1984) Photosynthetic and stomatal responses of two mangrove species, Aegiceras corniculatum and Avicenia marina, to long term salinity and humidity conditions. Plant Physiol. 74, 1-6

Bauer, H., Martha, P. (1981) The $\mathrm{CO}_{2}$ compensation point of $\mathrm{C}_{3}$ plants - a re-examination. I. Interspecific variability. Z. Pflanzenphysiol. 103, 445-450

Bauer, H., Martha, P., Kirchner-Heiss, B., Mairhoffer, I. (1983) The $\mathrm{CO}_{2}$ compensation point of $\mathrm{C}_{3}$ plants - a re-examination. II. Intraspecific variability. Z. Pflanzenphysiol. 109, 143-154

Beyschlag, W. (1984) Photosynthese und Wasserhaushalt von Arbutus une do L. im Jahreslauf am Freilandstandort in Portugal. Gaswechselmessungen unter natürlichen Bedingungen und experimentelle Faktorenanalyse. Diss. Würzburg

Bunce, J.A. (1977) Nonstomatal inhibition of photosynthesis at low water potentials in intact leaves of species from a variety of habitats. Plant Physiol. 59, 348-350

Bunce, J.A. (1984) Effects of humidity on photosynthesis. J. Exp. Bot. 35, 1245-1251

Collatz, G.J. (1977) Influence of certain environmental factors on photosynthesis and photorespiration in Simmondsia chinensis. Planta 134, 127-132

Collatz, J., Ferrar, P.J., Slatyer, R.O. (1976) Effects of water stress and differential hardening treatments on photosynthetic characteristics of a xeromorphic shrub, Eucalyptus socialis, F. Muell. Oecologia 23, 95-105

Doley, D., Yates, D.J. (1976) Gas exchange of Mitchell grass [Astrelba lappacea (Lindl.) Domin] in relation to irradiance, carbon dioxide supply, leaf temperature and temperature history. Aust. J. Plant. Physiol. 3, 471-487

Farquhar, G.D., von Caemmerer, S., Berry, J.A. (1980) A biochemical model of photosynthetic $\mathrm{CO}_{2}$ assimilation in leaves of $\mathrm{C}_{3}$ species. Planta 149, 78-90

Forrester, M.L., Krotkov, G., Nelson, C.D. (1966) Effect of oxygen on photosynthesis, photorespiration and respiration in detached leaves. I. Soybean. Plant Physiol. 41, 422-427

Forseth, I.N., Ehleringer, J.R. (1983) Ecophysiology of two solar tracking desert winter annuals. III. Gas exchange responses to light, $\mathrm{CO}_{2}$ and VPD in relation to long-term drought. Oecologia 57, 344-351

Jenson, C.R. (1975) Effects of salinity in the root medium. II. Photosynthesis and transpiration in relation to superimposed water stress from change of evaporative demands and of root temperature for short periods. Acta Agric. Scand. $25,72-80$
Jolliffe, P.A., Tregunna, E.B. (1968) Effect of temperature, $\mathrm{CO}_{2}$ concentration, and light intensity on oxygen inhibition of photosynthesis in wheat leaves. Plant Physiol. 43, 902-906

Kaiser, W.M. (1984) Response of photosynthesis and dark$\mathrm{CO}_{2}$-fixation to light, $\mathrm{CO}_{2}$ and temperature in leaf slices under osmotic stress. J. Exp. Bot. 35, 1145-1155

Kirschbaum, M.U.F., Farquhar, G.D. (1984) Temperature dependence of whole-leaf photosynthesis in Eucalyptus pauciflora Sieb. ex Spreng. Aust. J. Plant Physiol. 11, 519-538

$\mathrm{Ku}$, S.-B., Edwards, G.E. (1977) Oxygen inhibition of photosynthesis. II. Kinetic characteristics as affected by temperature. Plant Physiol. 59, 991-999

Lange, O.L., Meyer, A. (1979) Mittäglicher Stomataschluß bei Aprikose (Prunus armeniaca) and Wein (Vitis vinifera) im Freiland trotz guter Bodenwasser-Versorgung. Flora 168, $511-528$

Lange, O.L., Tenhunen, J.D. (1984) A minicuvette system for measurement of $\mathrm{CO}_{2}$ exchange and transpiration of plants under controlled conditions in field and laboratory. Heinz Walz Mess- und Regeltechnik, Effeltrich, FRG

Lange, O.L., Lösch, R., Schulze, E.-D., Kappen, L. (1971) Responses of stomata to changes in humidity. Planta $\mathbf{1 0 0}$, $76-86$

Lange, O.L., Beyschlag, W., Meyer, A., Tenhunen, J.D. (1984) Determination of photosynthetic capacity of lichens in the field - a method for measurement of light response curves at saturating $\mathrm{CO}_{2}$ concentration. Flora 175, 283-293

Leach, J.E. (1979) Some effects of air temperature and humidity on crop and leaf photosynthesis, transpiration and resistance to gas transfer. Ann. Appl. Biol. 92, 287-297

Leuning, R. (1983) Transport of gases into leaves. Plant Cell Environ. 6, 181-194

Lösch, R., Tenhunen, J.D. (1981) Stomatal responses to humidity - phenomenon and mechanism. In: Society for Experimental Biology, vol. 8: Stomatal physiology, pp. 137-161, Jarvis, P.G., Mansfield, T.A., eds. Cambridge University Press, Cambridge

Ludlow, M.M., Jarvis, P.G. (1971) Methods for measuring photorespiration in leaves. In: Plant photosynthetic production: Manual of methods, pp. 294-315, Sestak, Z., Catsky, J., Jarvis, P.G., eds. Dr. W. Junk N.V. Publishers, The Hague

Matthews, M.A., Boyer, J.S. (1984) Acclimation of photosynthesis to low leaf water potentials. Plant Physiol. 74, 161-166

Peisker, M., Ticha, I., Apel, P. (1979) Variations in the effect of temperature on oxygen dependence of $\mathrm{CO}_{2}$ gas exchange in wheat leaves. Biochem. Physiol. Pflanzen 174, 391-397

Powles, S.B., Critchley, C. (1980) Effect of light intensity during growth on photoinhibition of intact attached bean leaflets. Plant Physiol. 65, 1181-1187

Raschke, K. (1982) Involvement of abscisic acid in the regulation of gas exchange: evidence and inconsistencies. In: Plant growth substances 1982, pp. 581-590, Wareing, P.F., ed. Academic Press, London

Reseman, A., Raschke, K. (1984) Midday depressions in stomatal and photosynthetic activity of leaves of Arbutus unedo are caused by large water-vapor pressure differences between leaf and air. (Abstr.) Plant Physiol. 75, Suppl., 66

Schulze, E.-D., Lange, O.L., Evenari, M., Kappen, L., Buschbom, U. (1974) The role of air humidity and leaf temperature in controlling stomatal resistance of Prunus armeniaca L. under desert conditions. I. A simulation of the daily time course of stomatal resistance. Oecologia 17, 159-170

Schulze, E.-D., Lange, O.L., Kappen, L., Evenari, M., Buschbom, U. (1975a) The role of air humidity and leaf temperature in controlling stomatal resistance of Prumus armeniaca L. under desert conditions. II. The significance of leaf water 
status and internal carbon dioxide concentration. Oecologia 18, 219-233

Schulze, E.-D., Lange, O.L., Evenari, M., Kappen, L., Buschbom, U. (1975b) The role of air humidity and leaf temperature in controlling stomatal resistance of Prunus armeniaca L. under desert conditions. III. The effect on water use efficiency. Oecologia 19, 303-314

Sharkey, T.D. (1984) Transpiration-induced changes in the photosynthetic capacity of leaves. Planta 160, 143-150

Tenhunen, J.D., Lange, O.L., Pereira, J.S., Lösch, R., Catarino, F. (1981) Midday stomatal closure in Arbutus unedo leaves: Measurement with a steady-state porometer in the Portuguese evergreen scrub. In: Components of productivity in mediterranean-climate regions - Basic and applied aspects, pp. 61-69. Margaris, N.S., Mooney, H.A., eds. Dr. W. Junk Publishers, The Hague

Tenhunen, J.D., Lange, O.L., Gebel, J., Beyschlag, W., Weber, J.A. (1984) Changes in photosynthetic capacity, carboxylation efficiency, and $\mathrm{CO}_{2}$ compensation point associated with midday stomatal closure and midday depression of net $\mathrm{CO}_{2}$ exchange of leaves of Quercus suber. Planta 162, 193-203

Thompson, C.R., Stolzy, L.H., Taylor, O.C. (1965) Effect of soil suction, relative humidity and temperature on apparent photosynthesis and transpiration of rough lemon (Citrus jambhiri). Proc. Am. Soc. Hort. Sci. 87, 168-175

Troughton, J.H., Slatyer, R.O. (1969) Plant water status, leaf temperature, and the calculated mesophyll resistance to carbon dioxide of cotton leaves. Aust. J. Biol. Sci. 22, 815-827

von Caemmerer, S., Farquhar, G.D. (1981) Some relationships between the biochemistry of photosynthesis and the gas exchange of leaves. Planta 153, 376-387

Walter, H., Straka, H. (1970) Arealkunde: Floristisch-historische Geobotanik. Einführung in die Phytologie, Vol. 3 (2). Verlag Eugen Ulmer, Stuttgart

Received 15 December 1984; accepted 9 April 1985 